\title{
Management and Results of Ectopic Pregnancy Adapted by Clinical Guidelines: Two Years Experience of University Hospital in Turkey
}

\author{
Serpil Aydogmus, Serenat Eris, Hüseyin Aydogmus, Goncagül Gülbas Tanrısever, \\ Halime Sen Selim, Melike Demir Caltekin, Zeynep Cetinkaya Seyhanl, Sefa Kelekci \\ Gynecology and Obstetrics Department of Katip Celebi University Ataturk Training and Research Hospital, İzmir, \\ Turkey \\ Email: serenateris@hotmail.com
}

Received 4 July 2014; revised 4 August 2014; accepted 1 September 2014

Copyright (C) 2014 by authors and Scientific Research Publishing Inc.

This work is licensed under the Creative Commons Attribution International License (CC BY). http://creativecommons.org/licenses/by/4.0/

(c) (i) Open Access

\begin{abstract}
Ectopic pregnancy is defined as the fertilized ovum implants in a location outside the endometrial cavity, remains to be an important cause of maternal morbidity and mortality worldwide and is a health problem with incidence ranges between $0.25 \%$ and $2 \%$ of all pregnancies. In our study, in Izmir Katip Celebi University Ataturk Training and Research Hospital, Department of Obstetrics and Gynecology from 2011 to 2013, 96 cases with diagnosis of ectopic pregnancy managed by the adapted RCOG's Guide were analyzed retrospectively. The data were analyzed as follows: age, the history of operation, smoking, the presence of intrauterine device, blood groups, hemoglobin, platelets, values of B-hCG, the diagnostic interval, intra-abdominal free fluid and/or acute abdomen, the method of treatment and the success of treatment.
\end{abstract}

\section{Keywords}

Ectopic Pregnancy, Management, Tubal Pregnancy, Risk Factors

\section{Introduction}

Ectopic pregnancy is a pregnancy in which fertilized ovum implants other than the endometrial lining of the uterus. It is a common life-threatening emergency with incidence ranges between $0.25 \%$ and $2 \%$ of all pregnancies and the leading cause of pregnancy-related deaths in the first trimester [1]. There is an increase in its inciHow to cite this paper: Aydogmus, S., Eris, S., Aydogmus, H., Tanrısever, G.G., Selim, H.S., Caltekin, M.D., Seyhanlı, Z.C. and Kelekci, S. (2014) Management and Results of Ectopic Pregnancy Adapted by Clinical Guidelines: Two Years Experience of University Hospital in Turkey. Open Journal of Obstetrics and Gynecology, 4, 766-770. 
dence associated with rising in pelvic infections, advances in assisted reproductive technology, use of intrauterine devices and earlier diagnosis with more sensitive methods [2]. Although it is a relatively common entity, the treatment of ectopic pregnancy still presents challenges. Management of ectopic pregnancy has dramatically moved away from a primarily surgical approach [3]. Currently, most women with unruptured ectopic pregnancies are treated with medically. However, some women undergo surgical therapy by choice or by necessity, if they are not good candidates for medical therapy.

The aim of this study is to present the management and outcomes of patients with the diagnosis of ectopic pregnancy adapted by clinical guidelines over two years period in our clinic.

\section{Materials and Methods}

This was a cross sectional study with retrospective data collection of all the cases with diagnosis of ectopic pregnancy managed by the adapted RCOG's Guide at Izmir Katip Celebi University Ataturk Training and Research Hospital, Department of Obstetrics and Gynecology between 2011-2013. 96 cases with diagnosis of ectopic pregnancy were identified from the records. The information on the age, parity, the history of operation, smoking, the presence of intrauterine device (IUD), blood groups, haemoglobin, platelets, values of B-hCG, the diagnostic interval, intra-abdominal free fluid and/or acute abdomen, the treatment method and the success of treatment were extracted from the case files. The inclusion criteria for medical management of ectopic pregnancy was haemodynamic stability, absence of cardiac activity in an ectopic pregnancy, serum B-hCG level less than $3000 \mathrm{IU} / \mathrm{L}$ or the desire of patient by informed consent while B-hCG level more than $3000 \mathrm{IU} / \mathrm{L}$ [4]. The inclusion criteria for expectant management was haemodynamic stability with decreasing hCG levels that are less than $1000 \mathrm{IU} / \mathrm{L}$ at initial presentation and less than $100 \mathrm{ml}$ fluid in the pouch of Douglas [4]. Permission to conduct this study was sought from and granted by the study hospital's Ethical Committee. The data was analyzed with simple descriptive statistics and presented in frequency charts and tables.

\section{Results}

In the 2 year period, there were a total of 2738 deliveries and 96 ectopic gestations, recorded. This gives an incidence of 3.5\% of total deliveries. Total of 96 ectopic pregnancy; 1 of them was cornual, 1 of them was cervical and 2 of them was cesarean scar pregnancy while remaining 92 (95.8\%) patients had tubal ectopic pregnancy. Patients' demographic data, are classified according to expectant, medical and surgical treatment modalities, was presented in Table 1. The median age of patients with diagnosis of ectopic pregnancy was 30.1. The average of gravida was 2.7, parity was 1.3 and there was no significant difference between the groups. 64 patients underwent surgical treatment, 34 (53.1\%) of them underwent laparoscopic salpingostomy, 8 (12.5\%) of them underwent laparoscopic salpingectomy and 1 (1.5\%) of them underwent cornual resection while 20 (31.25\%) of them underwent salpingectomy by laparatomy and 1 (1.5\%) of them underwent salpingo-oophorectomy by laparatomy. In the group which underwent surgical treatment, smoking and history of IUD was significantly higher. Totally 41 (42.7\%) of 96 patients had a history of previous abdominal surgery, 34 of them were cesarean section, 2 of them were ectopic pregnancy and 1 of them was myomectomy operation.

Table 1. Demographic data classified according to treatment modalities.

\begin{tabular}{ccccc}
\hline & \multicolumn{4}{c}{ Treatment Modality } \\
\cline { 2 - 5 } & $\begin{array}{c}\text { Expectant } \\
(\mathrm{n}=13)\end{array}$ & $\begin{array}{c}\text { Medical Treatment } \\
(\mathrm{n}=19)\end{array}$ & $\begin{array}{c}\text { Surgery } \\
(\mathrm{n}=64)\end{array}$ & $\begin{array}{c}\text { Total } \\
(\mathrm{n}=96)\end{array}$ \\
\hline MEDIAN AGE (years) & 28.8 & 29.6 & 30.5 & 30.1 \\
HISTORY OF SURGERY (n) (percent) & $5(38.5 \%)$ & $8(32.1 \%)$ & $28(43.8 \%)$ & $41(42.7 \%)$ \\
GRAVIDA MEDIAN (n) & 2.7 & 2.4 & 2.7 & 2.7 \\
PARITY MEDIAN (n) & 1.5 & 1.0 & 1.4 & 1.3 \\
HISTORY OF SMOKING (n) (percent) & $2(15.4 \%)$ & $5(26.3 \%)$ & $15(23 \%)$ & $22(22.9 \%)$ \\
USE OF AN INTRAUTERINE DEVICE & $1(7.7 \%)$ & $1(5.3 \%)$ & $7(10.9 \%)$ & $9(9.4 \%)$ \\
\hline
\end{tabular}


In the Table 2, the medical and laboratory findings classified according to treatment modality at the time of admission and success status by the treatment modality were presented. The average time after last menstrual date of patients on admission was similar between groups and the mean time was 39.1 days. There were significant differences about the average values of B-HCG on admission between treatment groups. While the average of B-hCG levels was 844.1 IU/L in the observation group, $3263.1 \mathrm{IU} / \mathrm{L}$ in the group with medical treatment, $4609.9 \mathrm{IU} / \mathrm{L}$ in the group with surgical treatment. On admission the average of $\mathrm{Hb}$ was $9.9 \mathrm{~g} / \mathrm{dL}$ in the group underwent surgery, whereas the average of $\mathrm{Hb}$ was over $11 \mathrm{~g} / \mathrm{dL}$ in the other two groups. Almost all the patients with intra-abdominal free fluid and/or acute abdomen had been treated surgically. Methotrexate (MTX $50 \mathrm{mg} / \mathrm{m}$ $2 \mathrm{im}$ ) was administered to 18 of 19 patients for medical treatment. Local potassium chloride (KCl) was used for one of the patients. Second dose methotrexate was administered to 7 of the 11 patients who had failed methotrexate, in addition to the time one of these patients with cervical ectopic pregnancy, was applied dilation \& curettage procedure twice. The other four patients who had failed methotrexate were operated, two of them were made salpingostomy and two of them were made salpingectomy.

\section{Discussion}

Ectopic pregnancy is defined as the implantation of the fertilized ovum in a location outside the endometrial cavity, remains to be an important cause of maternal morbidity and mortality worldwide and is a health problem with incidence ranges between $0.25 \%$ and $2 \%$ of all pregnancies [1].

Exact etiology of ectopic pregnancy is still not known. Pathogenesis of ectopic pregnancy remains multifactorial. Identified risk factors include pelvic inflammatory disease, history of tubal and abdominal surgery, smoking, the use of progestin contraceptive, assisted reproduction, induced abortion [2]. These risk factors share a common mechanism of action — namely interference with the ciliary functions of fallopian tube [3].

Past pelvic surgery can favor adhesion formation and thus may distort the fallopian tubes. Vaswani et al. reported the risk of ectopic pregnancy 3 times increased in women with previous pelvic surgery [5]. Results of our study are in agreement with this study and revealed an association between history of surgery and ectopic pregnancy.

A strong association between smoking and ectopic pregnancy has been demonstrated by several studies [6] [7]. Smoking cessation reduces the risk of ectopic pregnancy to a level intermediate between that of current smokers and that of woman who have never smoked [8]. Our study confirmed this association that $22.9 \%$ of our patients were smokers.

Age has long been suspected to play a role in ectopic pregnancy risk but studies has provided conflicting results [9] [10]. Bouyer study showed that age plays an important role and increases the probability of exposure to other risk factors that predisposes the woman for ectopic pregnancy such as multiparity, abortions and age-related changes in tubal function [8]. The mean age of 30 years in our study is similar to the report of Arup Kumar et al. which corresponds to the age of reproduction and peak sexual activity [11].

Table 2. Medical and laboratory findings and treatment success classified according to treatment modalities of patients on admission.

\begin{tabular}{lcccc}
\hline & \multicolumn{3}{c}{ Treatment Modality } \\
\cline { 2 - 4 } & $\begin{array}{c}\text { Expectant } \\
(\mathrm{n}=13)\end{array}$ & $\begin{array}{c}\text { Medical Treatment } \\
(\mathrm{n}=19)\end{array}$ & $\begin{array}{c}\text { Surgery } \\
(\mathrm{n}=64)\end{array}$ & $\begin{array}{c}\text { Total } \\
(\mathrm{n}=96)\end{array}$ \\
\hline AVARAGE DAYS AFTER LAST MENSTRUAL PERIOD (Day) & 38.1 & 41.2 & 38.7 & 39.1 \\
MEAN ADMISSION B-hCG LEVELS (IU/L) & 844.1 & 3263.1 & 4609.9 & 3833.4 \\
MEAN ADMISSION HB LEVELS (g/dL) & 11.1 & 11.4 & 9.9 & 10.4 \\
$\begin{array}{l}\text { PATIENTS WITH FREE FLUID IN THE PERITONEAL } \\
\text { CAVITY ON ADMISSION (n) (percent) }\end{array}$ & $2(15.4 \%)$ & $1(5.3 \%)$ & $38(59.4 \%)$ & $41(42.7 \%)$ \\
PATIENTS WITH ACUTE ABDOMEN ON ADMISSION (n) (percent) & 0 & $1(5.3 \%)$ & $23(35.9 \%)$ & $24(25 \%)$ \\
FAILURE OF THE TREATMENT (n) & 0 & $11(57.8 \%)$ & 0 & $11(11.4 \%)$ \\
\hline
\end{tabular}


Ectopic pregnancy can be managed by laparotomy, operative laparoscopy, medically and occasionally by observation alone. Management must be tailored to the clinical condition and future fertility requirements of the woman [4].

Different features of ectopic pregnancy (initial serum hCG level, the presence of fetal cardiac activity, the size of ectopic mass) have been taken into consideration when deciding methotrexate (MTX, folic acid antagonist) treatment success. In the published literatures the initial serum hCG is probably the single most important factor in predicting the likely success of MTX which drops sharply from 96\% at levels between 2000 - 4999 IU/L, to 86\% for levels between 5000 - 9999 IU/L [12]. This necessarily limits the number of women with ectopic pregnancies eligible for medical management. Although medical therapy can be successful at serum hCG concentrations considerably higher than 3000 IU/L, quality-of-life data suggest that methotrexate is only an attractive option for women with an hCG below 3000 IU/L [13] [14]. Our data showed higher levels of mean admission B-hCG in surgery group in accordance with this information.

Data concerning the effect of ectopic pregnancy size on outcome are less clear but women with large adnexal masses are more likely to have already ruptured [15]. Additionally, the presence of cardiac activity in an ectopic pregnancy is associated with a reduced chance of success following medical therapy and should be considered a contraindication to medical therapy [3] [16].

Expectant management is a useful form of treatment management for ectopic pregnancy in selected cases. It is however only acceptable if it involves minimal risks to the woman. Expectant management should only be used for asymptomatic women with an ultrasound diagnosis of ectopic pregnancy, with no evidence of blood in the pouch of Douglas and decreasing hCG levels that are less than hCG $1000 \mathrm{iu} / \mathrm{l}$ at initial presentation and less than $100 \mathrm{ml}$ fluid in the pouch of Douglas [4].

Surgical treatment may involve salpingectomy, where the pregnancy is removed en bloc with the tube and salpingostomy, where the ectopic pregnancy removed with forceps or irrigation with conservation of the tube. Laparoscopy is cost-effective and is the preferred surgical approach [17] [18]. Laparotomy is reserved for patients with extensive intraperitoneal bleeding and/or acute abdomen.

Observational studies indicate that among women treated with salpingostomy as compared with those treated with salpingectomy, rates of subsequent intrauterine pregnancy are higher (73\% vs. 57\%) but that rates of subsequent ectopic pregnancy are also higher (15\% vs. 10\%) [17] [19]. Postoperative serial monitoring of hCG values is required after salpingostomy because trophoblastic cells remain in the fallopian tube in 5\% to $20 \%$ of women [20]. The decision to perform a salpingostomy or salpingectomy is often made intraoperatively on the basis of the extent of damage to the affected and contralateral tubes, but it is also dependent on the patient's history of ectopic pregnancy and wish for future fertility, the availability of assisted reproductive technology, and the skill of the surgeon. The use of conservative surgical techniques exposes women to a small risk of tubal bleeding in the immediate postoperative period and the potential need for further treatment for persistent trophoblast. Both these risks and the possibility of further ectopic pregnancies in the conserved tube should be discussed if salpingotomy is being considered by the surgeon or requested by the patient.

\section{Conclusions}

The management of ectopic pregnancy with an increased frequency can be performed by expectant management, medical and conservative/radical surgery depending on the patients' and techniques condition. In this study, we presented the treatment modalities, the management and results of our patients with the diagnosis of ectopic pregnancy adapted by clinical guidelines over two years period to shed light on other clinicians.

In conclusion women should be carefully advised, whenever possible, of the advantages and disadvantages associated with each approach used for the treatment of ectopic pregnancy and should participate fully in the selection of the most appropriate treatment.

\section{References}

[1] Omokanye, L.O., Balogun, O.R., Salaudeen, A.G., Olatinwo, A.W. and Saidu, R. (2013) Ectopic Pregnancy in Ilorin, Nigeria: A Four Year Review. Nigerian Postgraduate Medical Journal, 20, 341-345.

[2] Ayaz, A., Emam, S. and Farooq, M.U. (2013) Clinical Course of Ectopic Pregnancy: A Single-Center Experience. Journal of Human Reproductive Sciences, 6, 70-73. http://dx.doi.org/10.4103/0974-1208.112386

[3] Yao, M. and Tulandi, T. (1997) Current Status of Surgical and Nonsurgical Management of Ectopic Pregnancy. Fertil- 
ity and Sterility, 67, 421. http://dx.doi.org/10.1016/S0015-0282(97)80064-7

[4] Royal College of Obstetricians and Gynaecologists (2010) The Management of Tubal Pregnancy. RCOG Guideline No. 21.

[5] Vaswani, P. and Vaswani, R. (2013) Evaluation of Risk Factors for Ectopic Pregnancy among Women Attending a Tertiary Care Hospital in United Arab Emirates: A Case Control Study. Sri Lanka Journal of Obstetrics and Gynaecology, 35, 53-57.

[6] Handler, A., Davis, F., Ferre, C. amd Yeko, T. (1989) The Relationship of Smoking and Ectopic Pregnancy. American Journal of Public Health, 79, 1239-1242. http://dx.doi.org/10.2105/AJPH.79.9.1239

[7] Coste, J., Job-Spira, N. and Fernandez, H. (1991) Increased Risk of Ectopic Pregnancy with Maternal Cigarette Smoking. American Journal of Public Health, 81, 199-201. http://dx.doi.org/10.2105/AJPH.81.2.199

[8] Bouyer, J., Coste, J., Shojaei, T., Pouly, J.L., Fernandez, H., Gerbaud, L. and Job-Spira, N. (2003) Risk Factors for Ectopic Pregnancy: A Comprehensive Analysis Based on a Large Case-Control, Population-Based Study in France. American Journal of Epidemiology, 157, 185-194. http://dx.doi.org/10.1093/aje/kwf190

[9] Thorburn, J., Philipson, M. and Lindblom, B. (1986) Background Factors of Ectopic Pregnancy: II. Risk Estimation by Means of a Logistic Model. European Journal of Obstetrics, Gynecology, and Reproductive Biology, 23, 333-340. http://dx.doi.org/10.1016/0028-2243(86)90168-1

[10] Mäkinen, J.I. (1989) Increase of Ectopic Pregnancies in Finland. Combination of Time and Cohort Effect. Obstetrics and Gynecology, 73, 21-24.

[11] Arup, K.M., Niloptal, R., Kakali, S.K. and Pradip, K.B. (2007) Ectopic Pregnancy: An Analysis of 180 Cases. Journal of the Indian Medical Association, 105, 308-314.

[12] Menon, S., Colins, J. and Barnhart, K.T. (2007) Establishing a Human Chorionic Gonadotropin Cutoff to Guide Methotrexate Treatment of Ectopic Pregnancy: A Systematic Review. Fertility and Sterility, 87, 481-484. http://dx.doi.org/10.1016/j.fertnstert.2006.10.007

[13] Sowter, M., Farquhar, C. and Gudex, G. (2001) An Economic Evaluation of Single Dose Systemic Methotrexate and Laparoscopic Surgery for the Treatment of Unruptured Ectopic Pregnancy. British Journal of Obstetrics and Gynaecology, 108, 204-212.

[14] Mol, B., Hajenius, P., Engelsbel, S., Ankum, W., Hemrika, D., Van der Veen, F. and Bossuyt, P.M.M. (1999) Treatment of Tubal Pregnancy in the Netherlands: An Economic Comparison of Systemic Methotrexate Administration and Laparoscopic Salpingostomy. American Journal of Obstetrics \& Gynecology, 181, 945-951. http://dx.doi.org/10.1016/S0002-9378(99)70330-3

[15] Lipscomb, G., McCord, M., Stovall, T., Huff, G., Portera, S. and Ling, F. (1999) Predictors of Success of Methotrexate Treatment in Women with Tubal Ectopic Pregnancies. New England Journal of Medicine, 341, 1974-1978. http://dx.doi.org/10.1056/NEJM199912233412604

[16] Sowter, M. and Frappell, J. (2002) The Role of Laparoscopy in the Management of Ectopic Pregnancy. Reviews in Gynaecological Practice, 2, 73-82. http://dx.doi.org/10.1016/S1471-7697(02)00007-2

[17] Mol, F., Mol, B.W., Ankum, W.M., Van der Veen, F. and Hajenius, P.J. (2008) Current Evidence on Surgery, Systemic Methotrexate and Expectant Management in the Treatment of Tubal Ectopic Pregnancy: A Systematic Review and Meta-Analysis. Human Reproduction Update, 14, 309-319. http://dx.doi.org/10.1093/humupd/dmn012

[18] Hajenius, P.J., Mol, F., Mol, B.W., Bossuyt, P.M., Ankum, W.M. and Van der Veen, F. (2007) Interventions for Tubal Ectopic Pregnancy. Cochrane Database of Systematic Reviews, 24, Article ID: CD000324.

[19] Seeber, B.E. and Barnhart, K.T. (2006) Suspected Ectopic Pregnancy. Obstetrics and Gynecology, 107, 399-413. Erratum. Obstetrics and Gynecology, 107, 955.

[20] Seifer, D.B., Gutman, J.N., Grant, W.D., Kamps, C.A. and DeCherney, A.H. (1993) Comparison of Persistent Ectopic Pregnancy after Laparoscopic Salpingostomy versus Salpingectomy at Laparotomy for Ectopic Pregnancy. Obstetrics and Gynecology, 81, 378-382. 
Scientific Research Publishing (SCIRP) is one of the largest Open Access journal publishers. It is currently publishing more than 200 open access, online, peer-reviewed journals covering a wide range of academic disciplines. SCIRP serves the worldwide academic communities and contributes to the progress and application of science with its publication.

Other selected journals from SCIRP are listed as below. Submit your manuscript to us via either submit@scirp.org or Online Submission Portal.
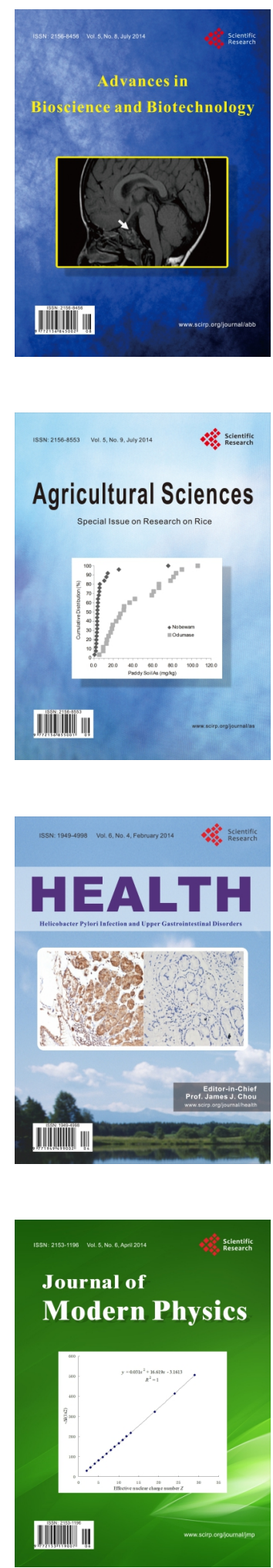
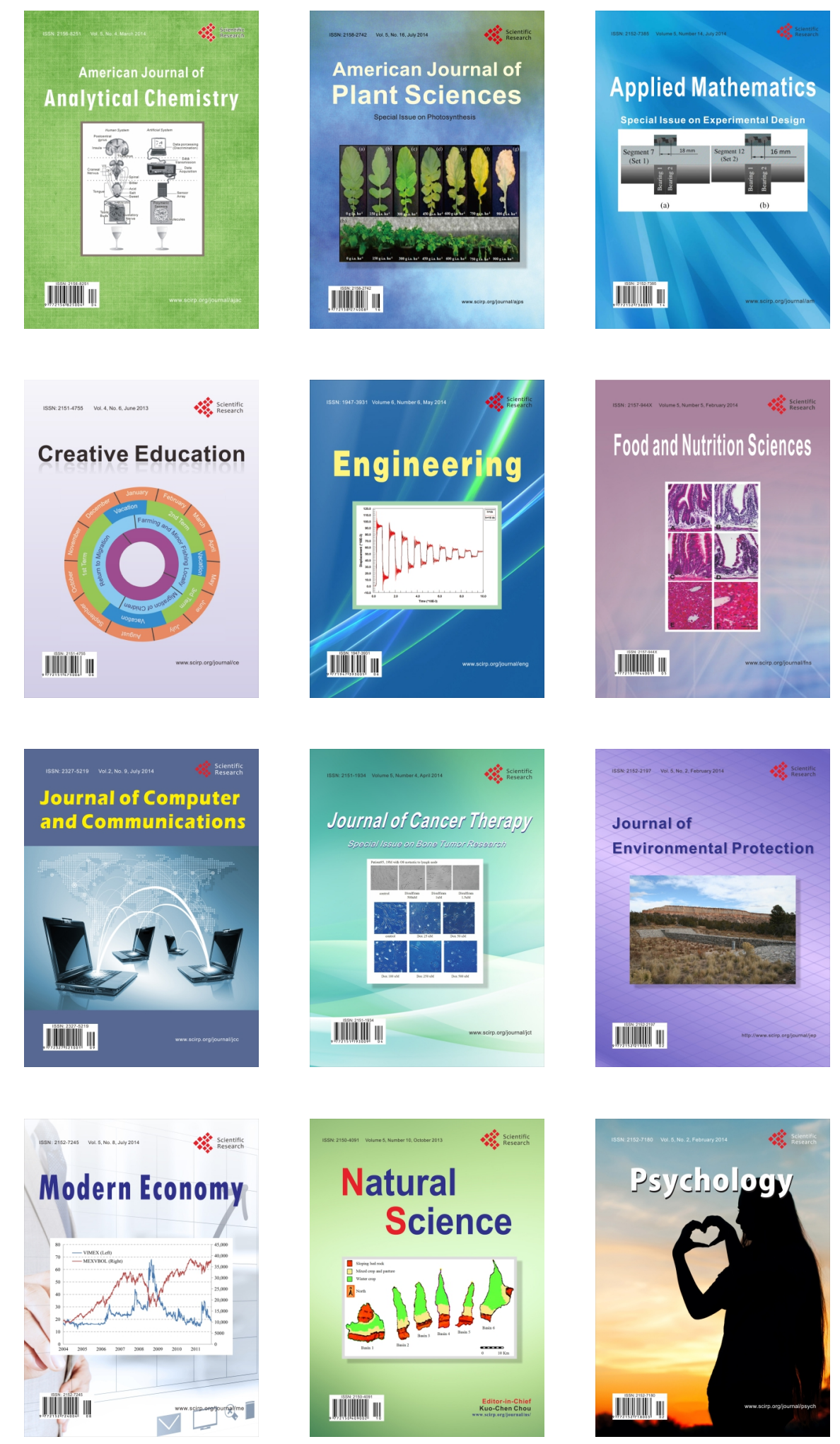